\title{
Obesity epidemic: we have to spend to save
}

\author{
Dr. Beer is head of the Food Science Department at the Swiss Federal Office of Public Health in Bern
}

For many years, a lasting impression of a visit to North America was the many overweight and obese people. Nowadays, the astonishment is much smaller, since excessive body weight became part of daily life in Western Europe. The results of the Swiss Health Survey in 1992/93 showed that $25 \%$ of the population was overweight and about $5 \%$ was obese. The 1997 Swiss Health Survey determined a further increase to $28 \%$ and $7 \%$, respectively (Eichholzer 1998; 2000). More than one third of the Swiss population has a BMI over $25 \mathrm{~kg} / \mathrm{m}^{2}$ ! Alarming is that obesity and overweight is not a problem limited to adults. Zimmermann and coworkers (2000; 2003) reported that - depending on which reference data were used - the prevalence of obesity in 6-12 year-old Swiss schoolchildren varied between 4 and $16 \%$ and the prevalence of overweight between 17 and $34 \%$. In view of the data by Mei (2003, in this issue) it is not that relevant if the percentage is 17 or $34 \%$ - although it is a considerable difference. More important, we must realise that once "acquired" overweight will most likely persist throughout life [Mei 2003].

The few excess pounds will weigh heavy later in life. In developed countries about $7.4 \%$ of the lost "disability-adjusted life years" (DALY) are attributed to obesity (WHO 2002) and obesity is the $5^{\text {th }}$ most important risk factor for disease burden. Obesity and overweight are accompanied by serious co-morbidities such as type 2 diabetes or cardiovascular disease. The risk of type 2 diabetes is increased up to 100fold by obesity and $80 \%$ of the prevalence of diabetes can be attributed to obesity and overweight.

The costs of treating diseases attributed to obesity and overweight are enormous. In Switzerland about $30 \%$ of the health care costs are caused by diet-related diseases. In 2000, total health care costs in Switzerland were estimated at 43 billion Swiss Francs (Bundesamt für Statistik 2002), therefore the costs caused directly or indirectly by obesity and overweight may be in the hundreds of millions of Swiss Francs.
From this perspective obesity and overweight represent an obvious risk to the health of the Swiss population. However, the perception of risk is very different in the general public as well as among specialists and politicians. The strong belief that chemical contaminants in food represent the largest health risk of eating is mirrored in the massive press coverage food scandals, such as the presence of antibiotics in poultry, normally get. Furthermore, many professionals in the food sector are convinced that microbiological hazards are the most important risk factor. Both problems are relevant to human health but food safety in Switzerland is on a very high level and successful programmes are in place to minimise exposure. Food-related risk perception in the general public and among specialists is far away from truth. Eating too much combined with too little physical activity is by far the most important risk factor of food to human health.

Therefore, it is time to take action and initiate programmes to prevent further weight gain of the Swiss population. The Swiss nutrition policy developed by the Nutrition Unit of the Swiss Federal Office of Public Health (SFOPH) serves as framework for implementing its nutrition-policy goals. Activities focus on increasing the consumption of fruit and vegetables, improving the eating habits of schoolchildren, raising folic acid intake in women of childbearing age, promoting breastfeeding and last but no least on encouraging people to maintain a healthy body weight. In autumn 2002 the health programme "Suisse Balance" (www.suissebalance.ch) was jointly initiated by the SFOPH and the Health Promotion Switzerland. "Suisse Balance" has the vision that Swiss eat a balanced diet and increase their physical activity level, aiming at a marked increase in the percentage of the Swiss population with a healthy body weight by 2010.

A budget of 2.9 million Swiss Francs is available to support local initiatives in the areas of youth, community and work place. 
"Suisse Balance" is a good start to fight excess body weight. However, more funds will be needed in the near future to allow accompanying public health campaigns and maintain monitoring programmes. As to cost-effectiveness, SFOPH will benefit from the knowledge gained implementing successful programmes in the infectious disease area. A recent demand for the advancement of nutrition information, education and training at the Swiss parliament (02.3135 Mo. Gutzwiller Felix, see www.parlament.ch) was positively received. Nevertheless, in view of the current economic situation it will be of high importance, if Swiss parliament is prepared to allocate more funds to nutrition prevention and health promotion.

The goal to prevent further weight gain of the Swiss population is a huge challenge to public health. Indeed, if we succeed, the invested money will result in a huge pay-back and will generate sustainable long-term benefits.

Michael U. Beer

\section{References}

Bundesamt für Statistik (2002). Kosten des Gesundheitswesens. Neuchâtel: Bundesamt für Statistik.

Eichholzer M (1998). Ernährungsdaten der Schweizerischen Gesundheitsbefragung 1992/93 In: Keller U, Lüthy J, Amadò R, et al., eds. Vierter Schweizer Ernährungsbericht. Bern: Bundesamt für Gesundheit: 237-60.

Eichholzer M, Bisig B, Gutzwiller F, Lüthy J (2000). Aktuelle Ernährungsprobleme in der Schweiz. Resultate der Schweizerischen Gesundheitsbefragung 1997. Mitt Lebensm Hyg 91: 251-73.
Mei Z, Gummer-Strawn LM, Scanlon KS (2003). Does overweight in infancy persist through the preschool years? An analysis of CDC Pediatric Nutrition Surveillance System data. Soz Praventiv Med 48: 161-7.

World Health Organization (2002). The world health report 2002: reducing risk, promoting healthy life. Geneva: WHO.

Zimmermann MB (2003). Schwere Kost. In Anonymous. www.ethlife.ethz.ch. Zürich: ETH Zürich.

Zimmermann MB, Hess SY, Hurrell, RF (2000). A national study of the prevalence of overweight and obesity in 6-12 y-old Swiss children: body mass index, body-weight perceptions and goals. Eur J Clin Nutr 54: 568-72.
Address for correspondence

Dr. Michael U. Beer

Swiss Federal Office of Public Health

Head Division of Food Science

CH-3003 Bern

Tel.: +4131322 9579

Fax: +4131322 9574

e-mail: michael.beer@bag.admin.ch

(10) To access this journal online: 